\title{
COMPOSITE MEMBRANES BASED ON SULFONATED POLYSULFONE AND NATURAL ZEOLITE FOR PROTON EXCHANGE MEMBRANE FUEL CELLS
}

\author{
Irfan Gustian*, Ghufira and Dwita Oktiarni \\ Department of Chemistry, Faculty of Mathematics and Natural Sciences \\ Universitas Bengkulu, Jalan Raya Kandang Limun, Bengkulu 38371, Indonesia. \\ *E-mail: Irfan.g@unib.ac.id
}

\begin{abstract}
Proton conducting composite membranes have been prepared via binary mixtures comprising sulfonated polysulfone (SPSU) and natural zeolite (NZ). Polysulfone has been sulfonated in 1, 2-dichloroethane using the homogeneous method with trimethylsilyl chlorosulfonate as sulfonating agent. The ratio of monomer mol and trimethylsilyl chlorosulfonate was 1:1.5. Natural zeolite was activated in $1 \mathrm{M}$ phosphoric acid and calcinated at $500^{\circ} \mathrm{C}$ for 4 hours. The sulfonated polysulfone was added with zeolite at mass ratios of 1:0.5, 1:1 and 1:1.5. The manufacture of composite membranes has been done by evaporating dimethyl formamide of each mass ratios. The composite membranes were characterized by FT-IR, XRD analysis, and conductivity $(\sigma)$. From the results of FT-IR spectra showed that interaction between sulfonated polysulfone and natural zeolite. From diffractogram showed that the diffractogram pattern after being blend with zeolite, the presence of crystal phase between $20-30^{\circ}$ at $2 \theta$. From the conductivity, the maximum proton conductivity was measured as $7.15 \times 10^{-4} \mathrm{~S} / \mathrm{cm}$ at $40^{\circ} \mathrm{C}$ for mass ratios of $1: 0.5$ and results, as well as literature data the possible proton conductivity mechanism of the membrane, has been modeled.
\end{abstract}

Keywords: Sulfonated polysulfone, natural zeolite, activated, mass ratio, conductivity.

@ RASĀYAN. All rights reserved

\section{INTRODUCTION}

Proton conducting composite membranes for a fuel cell has been widely used as alternative mobile and stationary power sources. The proton exchange membrane (PEM) is the key component in proton exchange membrane fuel cell which has the capability to transport protons from anodic to cathodic side. ${ }^{1-}$ ${ }^{4}$ The best-known example of PEM is DuPont's perfluorosulfonic acid type membrane (Nafion) which is most widely used both in fuel cell research and industry. The materials which have nonperfluorinated backbone were also developed as alternative membranes. Polysulfone (PS) is commonly used because of its have good mechanical property, cost, ease of processing, and thermal and chemical stability. PS is an aromatic polymer and can be sulfonated by treatment with various sulfonating agents. ${ }^{5,6}$ The great effort has been done for the development of novel proton exchange membranes. In this context, polymeric/inorganic composite membranes were identified as the alternative route by many research groups. In recent years, polymer composite membranes have been produced by many different approaches. Polymer composite membranes have a lot of advantages because of their dual functionality such as specific chemical stability and flexibility of the organic polymer backbone. ${ }^{7-12}$ Acid modified particles have better performance to improve the proton conductivity than unmodified filler. Superacids such as acid-modified zirconia have been preferred as filler for conducting membranes because of conductive groups that exist on its solid surface. ${ }^{13,14}$ Embedding acid-functionalized fillers can potentially enhance proton conductivity.

Recently, we have reported proton conducting membrane based on sulfonated polysulfone and activated natural zeolite. The present work discusses the production and characterization of proton conducting super acid composite membranes. To produce composite membranes, firstly zeolite was activated and sulfonation of polysulfone. Then the membrane materials were prepared in the presence of sulfonated

Rasayan J. Chem., 10(3), 689-694(2017)

http://dx.doi.org/10.7324/RJC.2017.1031716 
polysulfone (SPSU) and activated natural zeolite. Composite proton conducting membrane was evaluated in terms of the functional groups by FT-IR, diffractogram patterns by XRD, and proton conductivity by IM 3590 Chemical Impedance Analyzer HIOKI.

\section{EXPERIMENTAL}

\section{Materials}

Commercial polysulfone (PSU), trimethylsilyl chlorosulfonate (TMSCS) and methanol purchased from Aldrich, dimethylformamide and 1, 2-dichloroethane from Merck, and natural zeolite from Lembang West Java-Indonesia.

\section{Preparation}

Sulfonated polysulfone (SPSU) was prepared according to literature. ${ }^{15-17}$ The sulfonation degree (DS) of polysulfone was measured by acid-base titrimetric method. The sulfonation ratio of sulfonated polysulfone was calculated as $187 \%\left(\left(\mathrm{~mol} \mathrm{SO}_{3} \mathrm{H} /\right.\right.$ repeat unit $\left.) \times 100\right)$.

The preparation of proton-conductive composite membranes includes two steps which are as follows. Firstly zeolite was activated and then sulfonation of polysulfone. The membrane materials were prepared in the presence of sulfonated polysulfone (SPSU) and activated natural zeolite (NZ). SPSU and NZ have added at several mass ratios in DMF, i.e., SPSU:NZ; $1: 0.5,1: 1$, and 1:1.5. The mixtures were stirred overnight with mechanical stirring at $80{ }^{\circ} \mathrm{C}$. Solvent was evaporated in a vacuum oven at $60{ }^{\circ} \mathrm{C}$. To ensure complete solvent removal, the membranes were placed in a glove box at $50{ }^{\circ} \mathrm{C}$. Figure- 1 shows composite membranes SPSU: NZ; 1:0.5, 1:1, 1:1.5 and SPSU.

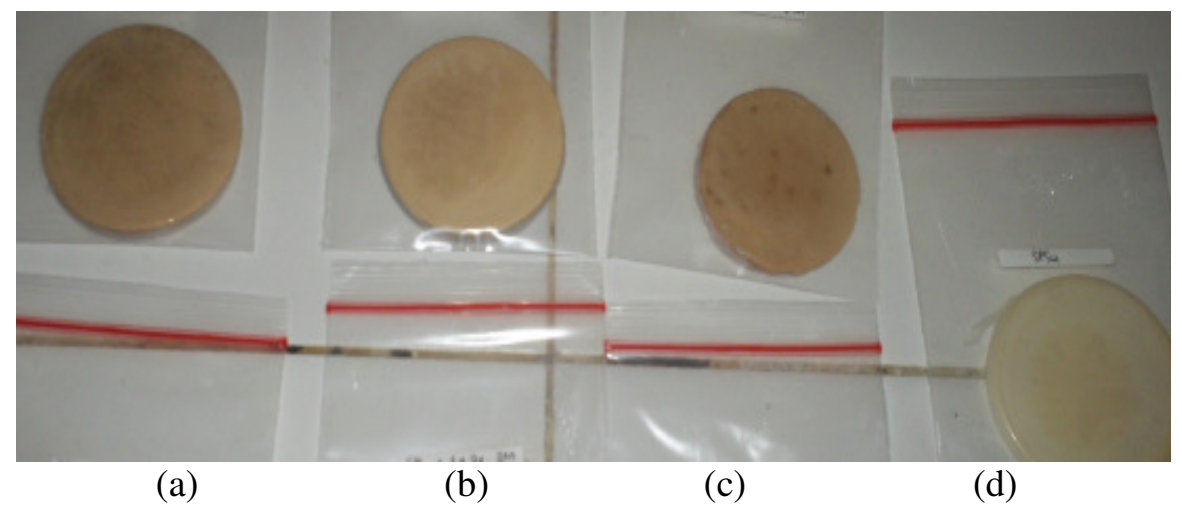

Fig.-1: Composite membranes SPSU: NZ; 1:0.5 (a), 1:1 (b), 1:1.5 (c) and SPSU (d).

\section{Characterization}

FT-IR spectra were recorded on a Bruker Alpha-P (Wismar, Germany) in attenuated total reflectance (ATR) in the range of $4000-400 \mathrm{~cm}^{-1}$. The X-ray powder diffraction (XRD) analysis was performed using X-ray diffractometer (Rigaku D-MAX2200, Japan) with $\mathrm{Cu} \mathrm{Ka}(\lambda=1.5406 \mathrm{~A})$ radiation over the range $2 \theta$ between $0^{\circ}$ and $70^{\circ}$. The conductivity of the membrane was measured by IM 3590 Chemical Impedance Analyzer HIOKI in frequency $1 \mathrm{KHz}, 0.05$ Volt and temperature between 30 and $80{ }^{\circ} \mathrm{C}$.

\section{RESULTS AND DISCUSSION}

Figure-2 shows the FTIR spectrum of polysulfone that has reported previously. ${ }^{17}$ Compared with the sulfonated spectrum, there is the difference. Differences in the spectrum of sulfonated polysulfone and polysulfone are particularly apparent in the area of the wavelength number $3700-2900 \mathrm{~cm}^{-1}$ and near the region 1310-1200 $\mathrm{cm}^{-1}$, where the polysulfone spectrum does not show the vibration of the $\mathrm{OH}$ strain and the symmetry $\mathrm{O}=\mathrm{S}=\mathrm{O}$ of the cluster sulfonate $-\mathrm{SO}_{3}$. It is also supported by the different types of spectrum bands obtained in the fingerprint region between polysulfone and sulfonated polysulfone. This phenomenon has been reported by previous studies. ${ }^{15-17}$ 


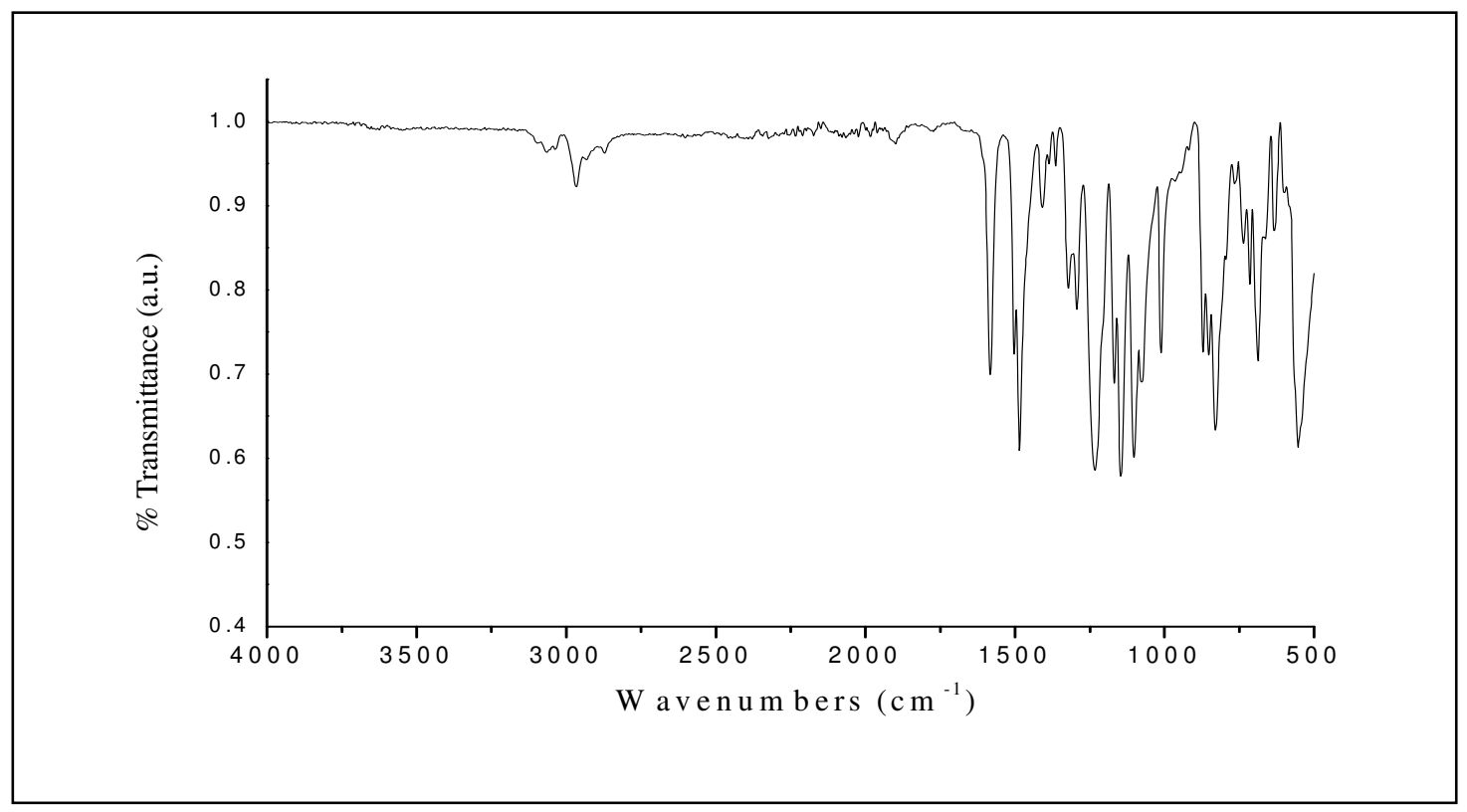

Fig.-2: FTIR spectrum of polysulfone ${ }^{17}$.

Figure-3 shows the spectra of sulfonated polysulfone (SPSU) and the composite membranes (SPSU: NZ 1:0.5, 1:1 and 1:1.5). Once blended with zeolite, all samples showed 6 similar bands in the area around $3440,1635,1223,1091,792,600 \mathrm{~cm}^{-1}$. The peak area of approximately $3440 \mathrm{~cm}^{-1}$ is the peak stretching of $\mathrm{O}-\mathrm{H}$, where water is absorbed in the cavity and zeolite channel. While the peak at about $1635 \mathrm{~cm}^{-1}$ corresponds to the bending mode of $\mathrm{O}-\mathrm{H}$ water. In addition, the broadband in the area of about $1091 \mathrm{~cm}^{-1}$, which is most prominent in the FTIR spectra, corresponds to the asymmetric internal stretching of the $\mathrm{SiO}_{4}$ or $\mathrm{AlO}_{4}$ vibration bands.

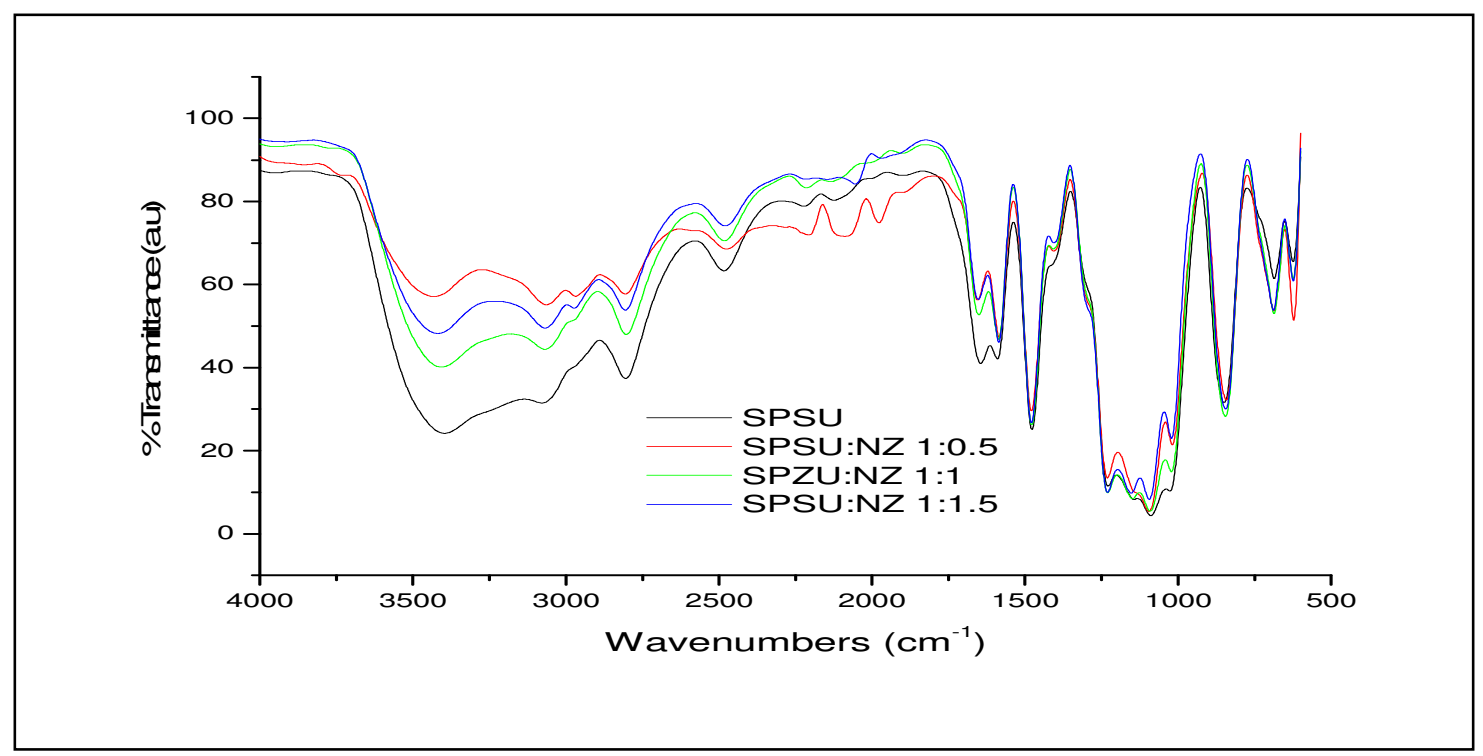

Fig.-3: Spectra of sulfonated polysulfone (SPSU) and the composite membranes (SPSU: NZ 1:0.5, 1:1 and 1:1.5). While the small bands observed at about $1223 \mathrm{~cm}^{-1}$ are for asymmetry stretching external vibration bands from $\mathrm{SiO}_{4}$ or $\mathrm{AlO}_{4}$. On the other hand, ribbons around $792 \mathrm{~cm}^{-1}$ and $600 \mathrm{~cm}^{-1}$ are due to the symmetric stretching of $\mathrm{SiO}_{4}$ or $\mathrm{AlO}_{4}$ and the vibrations of the double rings respectively. The small band observed at 
RASĀYAN J. Chem.

Vol. 10 | No. 3 |689 - 694 | July - September | 2017

about $600 \mathrm{~cm}^{-1}$ represents the blending mode for Si-O-Si. These wavenumbers have been reported previously. ${ }^{18}$

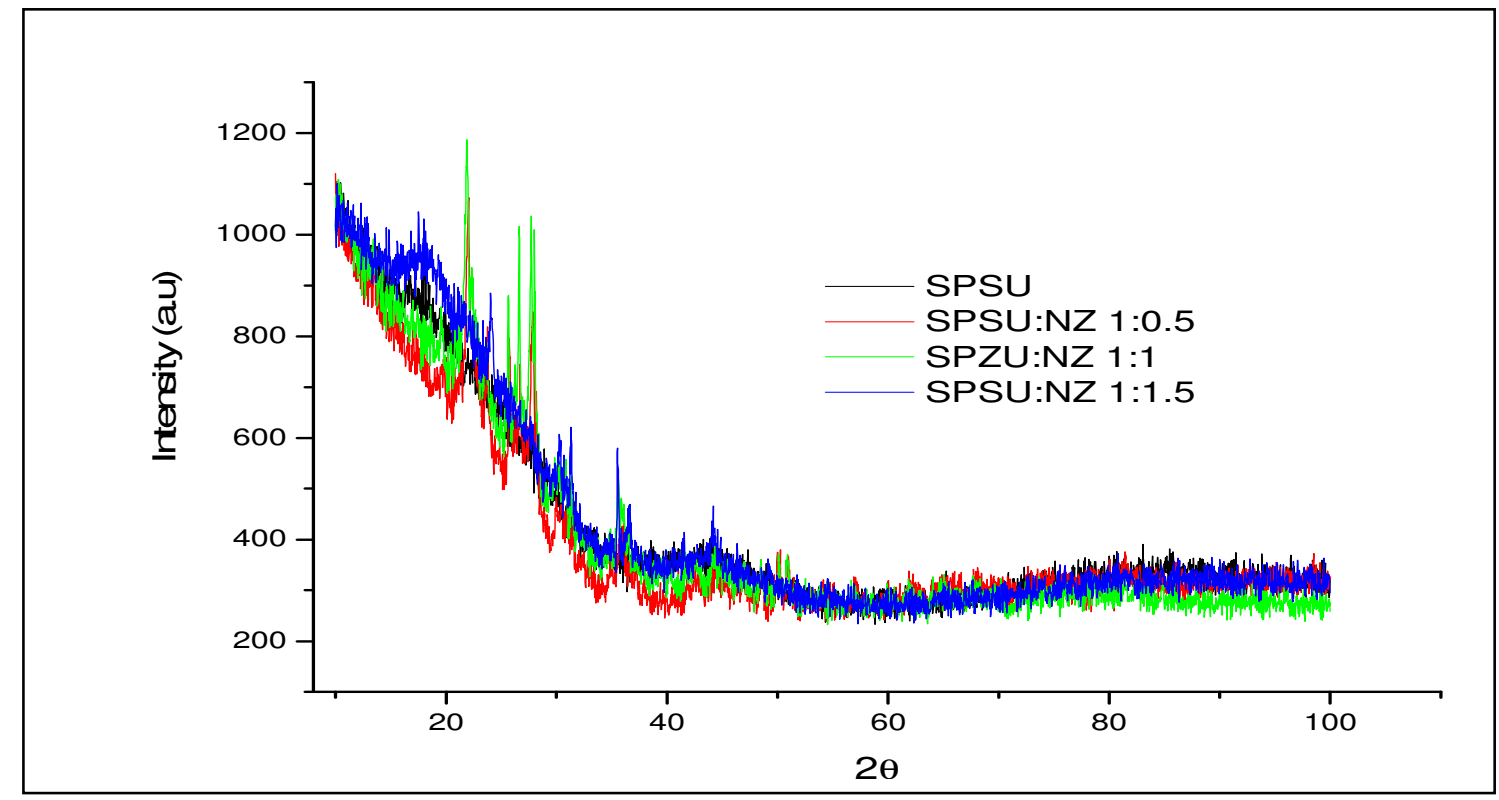

Fig.-4: Diffractogram of sulfonated polysulfone (SPSU) and the composite membranes (SPSU:NZ 1:0.5, 1:1 and 1:1.5).

Figure-4 shows the diffractogram of sulfonated polysulfone (SPSU) and the composite membranes (SPSU: NZ 1:0.5, 1:1 and 1:1.5). Sulfonated polysulfone itself generally exhibits a diffraction pattern with amorphous phases. Composite membranes SPSU: NZ; $1: 0.5$ has begun to show the peaks of the crystal phase in the region of $20-40^{\circ}$. Furthermore, the composition of $1: 1$ in the area $20-40^{\circ}$ the more obvious the influence of zeolite.

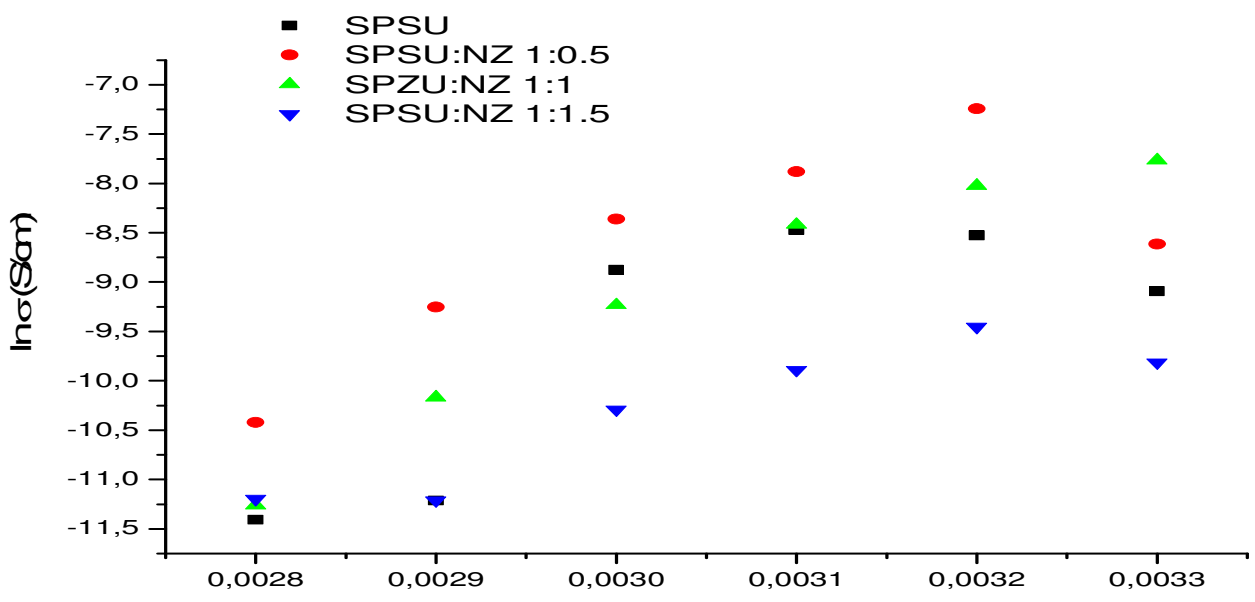

Fig.-5: DC conductivities of sulfonated polysulfone (SPSU) and the composite membranes (SPSU: NZ $1: 0.5,1: 1$ and $1: 1.5)$ as a function of reciprocal temperature.

In the composition of 1: 1.5 peaks in the area of $20-40^{\circ}$ begin to narrow. Overall the amorphous phase at $0-30^{\circ}$ is more dominant, the diffractogram pattern after being blending with zeolite, the presence of 
crystal phase between $20-40^{\circ}$ at an angle of $2 \theta$ this is a logical consequence due to the addition of zeolite. The basic pattern of zeolite diffractogram has been reported previously. ${ }^{19}$

Figure-5 Shows the DC conductivities of sulfonated polysulfone and composite membranes as a function of reciprocal temperature. It appears that the highest proton conductivity is present in the sulfonated polysulfone membrane that was blended by $0.5 \mathrm{~g}$ of zeolite. Conductivity was obtained at a temperature of $40{ }^{\circ} \mathrm{C}$ of $7.15 \times 10^{-4} \mathrm{~S} / \mathrm{cm}$. It is further demonstrated by $1 \mathrm{~g}$ of zeolite at a temperature of $30{ }^{\circ} \mathrm{C}$ of $4.249 \times 10^{-4} \mathrm{~S} / \mathrm{cm}$. Sulfonated polysulfone membrane was obtained at a temperature of $50{ }^{\circ} \mathrm{C}$ of $2.09 \times 10^{-}$

${ }^{4} \mathrm{~S} / \mathrm{cm}$. For sulfonated polysulfone membranes blending with $1.5 \mathrm{~g}$ of zeolite had maximum conductivity value of $7.85 \times 10^{-5} \mathrm{~S} / \mathrm{cm}$ at a temperature of $40{ }^{\circ} \mathrm{C}$. The previous study has reported that conductivity composite membranes based on sulfonated polysulfone and activated carbon has been measured as $8.8 \mathrm{x}$ $10^{-4} \mathrm{~S} / \mathrm{cm}$ at $40{ }^{\circ} \mathrm{C} .{ }^{17}$

The conductivity isotherm illustrates that the DC conductivities of SPSU-NZ composite membranes strongly depend on temperature as well as on the mass ratio of NZ. However, the DC conductivity illustrates that the NZ content increases the conductivity for SPSU-NZ: 1:0.5 composite membrane, and decreases the conductivity for SPSU-NZ; 1:1. One possible explanation is that complexation may occur between side acid units of $\mathrm{NZ}$ and $\mathrm{SO}_{3} \mathrm{H}$ groups of sulfonated polysulfone at 1:0.5 ratio of $\mathrm{NZ}$. Additional reason can be the partial reaction of zeolite resulting in loss of proton sources. Thus, at mass ratio 1:1 NZ ratio the proton conductivity decreased due to loss of proton by condensation.

The direct current (DC) conductivities strongly depends on the temperature and the mass ratio of NZ. From the temperature at $40^{\circ} \mathrm{C}$, we measured a conductivity of $7.15 \times 10^{-4} \mathrm{~S} / \mathrm{cm}$ for SPSU: NZ, 1:0.5. It has found that the membrane with a mass ratio of NZ 0.5 has a higher conductivity. When the NZ composition increased the proton conductivity also decreased. The major part of proton transport is provided over both acids from zeolite coordinated with $\mathrm{SO}_{3} \mathrm{H}$ groups of sulfonated polysulfone. In particular, there are two different types of transport mechanisms that contribute to the movement of protons on the proton conducting membrane. The first is through structural diffusion (Grotthuss mechanism) where proton conductivity is controlled by proton transport through dopant, Grotthuss proton transport. The second is through a vehicle mechanism, the proton runs through the species on a neutral or charged vehicle. Previous studies have reported the contribution of this mechanism to proton conductivity of pure dopant. ${ }^{20}$

The proposed proton transport model in composite membranes occurs through the structural diffusion of proton conductivity mainly controlled by proton transport. This mechanism of proton movement has known as the 'vehicle mechanism', the movement of protons occurs from one protonated site to the next protonation site, the proton can be transferred from protonated NZ molecule to neighbor non-protonated $\mathrm{NZ}$ molecule. Therefore, at $0.5 \mathrm{~g}$ addition of NZ, proton transfers occur rapidly to neighboring molecules with low activation energy, such as at $40{ }^{\circ} \mathrm{C}$. The movement of protons across the membrane follows the vehicle diffusion mechanism, it can be explained that $\mathrm{NZ}$ can replace the role of water to produce proton conductivity in the composite membranes at temperatures below $100{ }^{\circ} \mathrm{C}$.

\section{CONCLUSION}

In the present work, we have carried out sulfonation of polysulfone with sulfonation degree $187 \%$ using 1, 2-dichloroetana as a solvent and trimethylsilyl chlorosulfonate as a sulfonating agent with a mole ratio of 1:1.5. Composite membranes have been prepared by mixing the sulfonated polysulfone with natural zeolite with mass ratios 1:0.5, 1:1 and 1:1.5 in dimethylformamide, the proton conductivity of SPSU-NZ was measured as $7.15 \times 10^{-4} \mathrm{~S} / \mathrm{cm}$ at $40^{\circ} \mathrm{C}$ for membrane 1:0.5. The proton transport model of composite membranes is through a vehicle mechanism. These composite membranes can be suggested for application in polymer electrolyte membrane fuel cells (PEMFCs).

\section{ACKNOWLEDGMENT}

This work was supported by Penelitian Fundamental Kemenristek-Dikti Republic of Indonesia under the contract number 904/UN30.15/LT/2017. 
RASĀYAN J. Chem.

Vol. 10 | No. 3 |689 - 694 | July - September | 2017

\section{REFERENCES}

1. S.U. Celik, A. Bozkurt, S.S. Hosseini, Prog. Polym. Sci., 37, 1265 (2012).

2. F.M. Gray, Polymer Electrolytes; RSC Materials Monographs, 1st ed The Royal Society of Chemistry, Cambridge, (1997).

3. F. Babir, T. Gomez, Int. J. Hydrog. Energy, 21,891 (1996).

4. A. Aslan, Ü. Sen, A. Bozkurt, J. Electrochem. Soc., 156, B1112 (2009).

5. X. Li, C. Zhao, H. Lu, Z. Wang, H. Na, Polymer, 46, 5820 (2005).

6. J. Lee, C.S. Marvel, J. Polym. Sci. Polym. Chem. Ed., 22, 295 (1984).

7. Z. Durmus, H. Kavas, M.S. Mu Toprak, A. Baykal, T.G. Altincekic, A. Aslan, A. Bozkurt,S. Cosgun, J. Alloys Compd., 484, 371 (2009).

8. S.Y. Chen, C.C. Han, C.H. Tsai, J. Huang, Y.W. Chen-Yang, J. Power Sources, 171, 363 (2007).

9. A. Carbone, A. Sacca, I. Gatto, R. Pedicini, E. Passalacqua, Int. J. Hydrog. Energy, 33, 3153 (2008).

10. D. Yilser, E. Serdar, B. Nurcan, E. Inci, Int. J. Hydrog. Energy, 34, 3467 (2009).

11. T. Kobayashi, M. Rikukawa, K. Sanui, N. Ogata, Solid State Ionics, 106, 219 (1998).

12. Y. Jun, H. Zarrin, M. Fowler, Z. Chen, Int. J. Hydrog. Energy, 36, 6073 (2011).

13. E. Chalkova, M.B. Pague, M.V. Fedkin, D.J. Wesolowski, S.N. Lvov, J. Electrochem. Soc., 152, A1035 (2005).

14. V. Baglio, A.S. Aric'o, A.D. Blasi, V. Antonucci, P.L. Antonucci, S. Licoccia, Electrochim. Acta, 50, 1241 (2005).

15. I. Gustian, S.U. Çelik, A. Bozkurt, J. Mater. Res., 27, 2650 (2012).

16. I. Gustian, S.U. Çelik, A. Zainuddin, W. Suratno, A. Bozkurt, R. E. Siregar, J. Math. Fund. Sci., 46, 50 (2014).

17. I. Gustian, Asdim, E. Maryanti, Rasayan Journal Chemistry, 9 (4), 608 (2016).

18. K. Byrappa and B.V. Suresh Kumar, Asian Journal of Chemistry, 19 (6), 4933 (2007).

19. G. T. Kokotailo and C. A. Fyfe, The Rigaku Journal, 12 (1), 3 (1995).

20. S.U. Celik, A. Aslan, A. Bozkurt, Solid State Ionics, 179, 683 (2008).

[RJC-1716/2017] 